\title{
Progesterone-based fixed-time artificial insemination protocols for dairy cows: Gonadotropin-releasing hormone versus estradiol benzoate at initiation and estradiol cypionate versus estradiol benzoate at the end
}

\author{
L. F. Melo, ${ }^{*}$ P. L. J. Monteiro Jr., ${ }^{*}$ R. S. Surjus, ${ }^{*}$ J. N. Drum, ${ }^{*}$ M. C. Wiltbank, $†$ and R. Sartori ${ }^{* 1}$ \\ ${ }^{*}$ Department of Animal Science, University of São Paulo, Piracicaba, SP 13418-900 Brazil \\ †Department of Dairy Science, University of Wisconsin-Madison, Madison 53706
}

\begin{abstract}
Our objectives were to evaluate ovarian dynamics and fertility comparing 2 treatments at the start of a progesterone (P4)-based fixed-time artificial insemination (FTAI) protocol and 2 treatments at the end of the protocol. Thus, 1,035 lactating Holstein cows were assigned in a random phase of the estrous cycle to 1 of 4 treatments using a completely randomized design with a $2 \times 2$ factorial arrangement. At the beginning of the protocol $(\mathrm{d}-10)$, cows received $\mathrm{GnRH}$ or estradiol benzoate (EB) and, at the end, EB (d -1) or estradiol cypionate (ECP; $d-2$ ), resulting in 4 treatments: GnRH-EB, GnRH-ECP, EB-EB, and EB-ECP. All cows received an intravaginal $\mathrm{P} 4$ device on $\mathrm{d}-10$, which was removed on $\mathrm{d}-2$. Cows also received $\mathrm{PGF}_{2 \alpha}$ on $\mathrm{d}$ -3 and -2 . The FTAI was performed on $d 0$. Ovaries were evaluated by ultrasound for corpus luteum (CL) presence and regression ( $\mathrm{d}-10$ and -3$)$ and follicle measurements ( $\mathrm{d}-10$ and 0$)$, as well as the uterus for percentage pregnant per $\mathrm{AI}$ (P/AI; d 32 and 60). Blood samples were collected $(\mathrm{d}-10$ and -3$)$ for $\mathrm{P} 4$ measurements. Treatment with $\mathrm{GnRH}$ rather than EB tended to increase $\mathrm{P} / \mathrm{AI}$ on $\mathrm{d} 32$ (38.2 vs. $33.7 \%)$ and on $\mathrm{d} 60$ (32.9 vs. $28.9 \%)$. More cows treated with GnRH had CL on d -3 compared with EB-treated cows (77.3 vs. $58.3 \%$ ), due to less CL regression between $\mathrm{d}-10$ and -3 (24.7 vs. $43.8 \%)$ and more cows with a new CL on d -3 (35.9 vs. $25.0 \%)$. Cows treated with GnRH also had greater $\mathrm{P} 4$ concentrations on $\mathrm{d}-3$ than $\mathrm{EB}$ cows (3.4 vs. $2.0 \mathrm{ng} / \mathrm{mL}$ ). Increased circulating $\mathrm{P} 4$ at the start of the protocol $(\mathrm{d}-10)$ decreased the probability of ovulation to $\mathrm{EB}$ or $\mathrm{GnRH}$ at that time. Cows from $\mathrm{GnRH}$ group also ovulated a larger-diameter follicle at the end of the protocol (15.5 vs. $14.7 \mathrm{~mm}$ ). No difference between EB and ECP in P/AI on d 32 (34.8 vs. 37.0) and 60 (30.8 vs. $31.0 \%)$ or in pregnancy loss (11.1 vs. $15.4 \%)$ was de-
\end{abstract}

Received March 25, 2016.

Accepted July 4, 2016.

${ }^{1}$ Corresponding author: robertosartori@usp.br tected and we found no interaction between treatments for P/AI. Independent of treatment, cows with CL on $\mathrm{d}$ -10 and -3 had the greatest $\mathrm{P} / \mathrm{AI}$ on $\mathrm{d} 60(36.9 \%)$. In conclusion, treatments at the end of the protocol were similar for ECP or EB and we found no additive effect or interactions on $\mathrm{P} / \mathrm{AI}$ between treatments. However, cows treated with GnRH rather than EB on $d-10$ had less luteolysis and tended to have greater $\mathrm{P} / \mathrm{AI}$, probably because $\mathrm{P} 4$ concentrations were greater during the protocol. Finally, regardless of treatments, cows with CL at the beginning of the protocol as well as at the time of $\mathrm{PGF}_{2 \alpha}$ had greater fertility.

Key words: bovine, endocrine, fertility, synchronization

\section{INTRODUCTION}

In the United States, declining reproductive performance has been reported for more than $50 \mathrm{yr}$ (Washburn et al., 2002); however, this trend seems to have been reversed in about 2000 to 2002, with current reports of increasing reproductive efficiency as measured by daughter pregnancy rate or days open (Norman et al., 2009). The improvement in reproductive efficiency coincided with the introduction of programs for precise synchronization of ovulation and fixed-time AI (FTAI; Wiltbank and Pursley, 2014), although other changes during the last 2 decades, including improving genotype for fertility and management changes, could also be important factors in the upsurge in reproduction on commercial dairy herds. Classical protocols to manage the estrous cycle produced a synchronized estrus by using $\mathrm{PGF}_{2 \alpha}$ products or delivery systems for progesterone (P4) or progestin (Bó et al., 2002; Cavalieri et al., 2006). However, problems with detection of estrus and reductions in fertility were reported (Lopez et al., 2004). Protocols have now been developed that allow AI to be performed at a known time in relation to expected ovulation without the need for detection of estrus (Souza et al., 2008; Pereira et al., 2014), even in anovular cows (Stevenson et al., 2006). Numerous modifications and improvements to the original proto- 
cols have been completed (Pursley et al., 1995; Binelli et al., 2014; Wiltbank and Pursley, 2014). There are 3 main objectives for these protocols: (1) synchronization of follicular waves to optimize the period of follicular dominance to not ovulate too old (Cerri et al., 2009) or too young (Vasconcelos et al., 1999) of a follicle; (2) synchronization of corpus luteum (CL) function and circulating $\mathrm{P} 4$; and (3) synchronization of final ovulation with optimally scheduled FTAI. To achieve these objectives, most protocols use a combination of GnRH, $\mathrm{PGF}_{2 \alpha}, \mathrm{P} 4$ or progestin, or estradiol (E2) esters (Binelli et al., 2014) based on hormonal products approved for use in a specific country and attributes of different breeds, physiological conditions, and types of management.

Hormonal treatments at the initiation of a FTAI protocol are generally aimed at synchronizing the follicular wave by either ovulating a follicle using $\mathrm{GnRH}$ (Pursley et al., 1995; Vasconcelos et al., 2011) or suppressing current follicle growth using a combination of E2 and P4 (Burke et al., 1996; Bó et al., 2002; Cavalieri et al., 2006; Wiltbank and Pursley, 2014). Treatment with GnRH at protocol initiation, as done in many countries, can induce an LH surge, ovulate a dominant follicle, and thus initiate a synchronized new follicular wave; although the magnitude of these responses depends on stage of the estrous cycle when GnRH treatment is given (Vasconcelos et al., 1999; Rutigliano et al., 2008; Giordano et al., 2012b). Treatment with the initial GnRH on d 6 and 7 of the estrous cycle is the optimal time for ovulation and fertility; however, treatment with $\mathrm{GnRH}$ at a random reproductive stage generally results in ovulation in $50 \%$ or less of cows (Giordano et al., 2012b; Bilby et al., 2013; Bisinotto et al., 2013; Lopes et al., 2013). In contrast to GnRH, E2 or $\mathrm{P} 4$ treatments are used at the initiation of protocols in many countries and these protocols seem to be effective at most, if not all, stages of the estrous cycle (Monteiro et al., 2015). Starting protocols with E2 or P4 treatments suppresses circulating $\mathrm{LH}$ and FSH concentrations and regresses the follicles in the current follicular wave (Burke et al., 1996; Bó et al., 2002; Cavalieri et al., 2003; Wiltbank and Pursley, 2014), resulting in a synchronized follicular wave emergence 3 to $5 \mathrm{~d}$ later (Bó et al., 1993) depending on the dose and type of E2 ester (Burke et al., 2003). However, recent studies have reported that regression of the dominant follicle does not occur in all dairy cows following the standard treatment with $2 \mathrm{mg}$ of E2-benzoate (EB) and an intravaginal $\mathrm{P} 4$ implant at the initiation of a protocol and that treatment with a larger dose of EB at protocol initiation $(3 \mathrm{mg})$ does not improve follicle wave synchronization (Monteiro et al., 2015). Almost
$30 \%$ of the cows did not initiate a new follicular wave and thus ovulated a larger persistent follicle at the end of the protocol resulting in much lower pregnancy per AI (P/AI) in these cows (Monteiro et al., 2015). Further, in contrast to treatment with GnRH that can cause ovulation of an accessory CL and thus increase circulating P4 during growth of the ovulatory follicular wave (Souza et al., 2008), treatment with E2 esters can induce CL regression, potentially decreasing circulating P4 during ovulatory follicle growth (Monteiro et al., 2015). Several studies have indicated a lower P/AI when the preovulatory follicle develops in the presence of lower circulating P4 (Bisinotto et al., 2013; Wiltbank et al., 2014). Thus, advantages and disadvantages may exist to protocols initiated with GnRH or E2 and P4 in terms of synchronization of follicular waves, which seems to favor E2 and P4, and hormonal environment during growth of the ovulatory follicular wave, which seems to favor GnRH.

At the end of FTAI protocols ovulation is induced, generally by treatment with GnRH, EB, or E2-cypionate (ECP). The E2 esters are generally used at lower doses of EB or ECP at $0(\mathrm{ECP})$ or $24 \mathrm{~h}(\mathrm{~EB})$ after P4 implant removal, due to their pharmacodynamics, with these compounds producing a similar percentage of cows with synchronized ovulation but with differences in variability and timing of E2 peak, LH surge, and ovulation (Souza et al., 2009). Treatment with EB produced a circulating E2 peak at an earlier time, with greater peak E2, and of a shorter duration compared with ECP (Souza et al., 2005), which should lead to a better synchronized ovulation. Nevertheless, the longer duration of circulating E2 after ECP than EB may produce a better endocrine environment during proestrus (Binelli et al., 2014).

Thus, our overall objectives were to compare the ovarian dynamics and fertility using 2 different treatments at initiation of a FTAI protocol, GnRH versus $\mathrm{EB}$, combined with 2 different treatments at the end of the protocol, EB versus ECP. Thus, we had 3 specific hypotheses. (1) Initiation of a FTAI protocol with GnRH compared with EB would increase fertility in lactating dairy cows, due to improved endocrine environment during ovulatory follicle growth, in spite of reduced follicular wave synchronization. (2) Induction of ovulation at the end of the protocol with EB would improve fertility compared with ECP due to the expected more physiological pattern of circulating E2 during the proestrus period. (3) The effect of treatments at the beginning of the protocol and end of the protocol would be additive. Thus, 4 FTAI protocols were compared for ovarian dynamics and hormonal concentrations during the protocol and fertility at the end of each protocol. 


\section{MATERIALS AND METHODS}

This experiment was conducted in a single commercial dairy farm, located in São Pedro city, São Paulo, Brazil. The Animal Use Ethics Committee of Escola Superior de Agricultura "Luiz de Queiroz" (ESALQ), University of São Paulo approved all procedures involving cows in this study.

\section{Animals, Housing, and Diets}

For this study, a total of 1,035 lactating Holstein cows was used (363 primiparous and 672 multiparous). At the beginning of the experiment $(\mathrm{d}-10)$, cows averaged (mean \pm SD) $140.7 \pm 97.1$ DIM, yielding $36.9 \pm$ $9.33 \mathrm{~kg}$ of milk/d, with BCS of $2.8 \pm 0.29$ and in lactation $2.2 \pm 1.33$. Cows were housed in freestall barns with free access to water and mineral salt and fed ad libitum a TMR diet based on corn silage and Tifton 85 hay as forages and concentrate based on corn and soybean meal; minerals and vitamins were balanced to meet or exceed the nutritional requirements of lactating dairy cows (NRC, 2001). Throughout the experiment, cows were milked 3 times daily, 8 h apart.

\section{Protocols and Treatments}

Cows were randomly assigned to 1 of 4 treatment groups using a completely randomized design with a $2 \times 2$ factorial arrangement of treatments. Cows were assigned to 1 of 2 treatments at the beginning of the FTAI protocol $(\mathrm{d}-10)$ : EB $(\mathrm{n}=485)$, where cows received $2.0 \mathrm{mg}$ of EB (Gonadiol, MSD Saúde Animal, São Paulo, Brazil), or GnRH $(\mathrm{n}=550)$, where cows received $100 \mu \mathrm{g}$ of Gonadorelin (Fertagyl, MSD Saúde Animal). At the end of the protocol, cows were assigned to 1 of 2 treatments: ECP $(n=516)$, where on $d-2$ cows received $1.0 \mathrm{mg}$ of ECP (ECP, Zoetis, São Paulo, Brazil), or $\mathrm{EB}(\mathrm{n}=519)$, where on $\mathrm{d}-1$ cows received, 1.0 $\mathrm{mg}$ of EB. All cows received an intravaginal $\mathrm{P} 4$ implant containing $1.9 \mathrm{~g}$ of $\mathrm{P} 4$ [controlled internal drug release (CIDR), Zoetis] at initiation of the protocol $(\mathrm{d}-10)$. The implant was removed on $\mathrm{d}-2$. Two treatments with $500 \mu \mathrm{g}$ of cloprostenol sodium $\left(\mathrm{PGF}_{2 \alpha}\right.$, Sincrosin, Vallée S.A., São Paulo, Brazil), on d -3 and -2 , were administered in all cows. Use of $2 \mathrm{PGF}_{2 \alpha}$ treatments in this study was based on results from previous studies showing that treatment with only a single $\mathrm{PGF}_{2 \alpha}$ does not produce complete CL regression in all cows that were either treated with a GnRH protocol (Wiltbank et al., 2015) or an E2 and P4 protocol (Pereira et al., 2013b; Monteiro et al., 2015). Cows were inseminated on $\mathrm{d} 0$ at $48 \mathrm{~h}$ after removal of the $\mathrm{P} 4$ implant using conventional frozen and thawed semen from Holstein sires (Figure 1).

\section{BCS, DIM, Milk Yield, and Ovarian Structures}

At experiment enrollment, all cows were scored for body condition using a 1- to 5-point scale according to Ferguson et al. (1994). For this study, BCS was categorized into low $(\leq 2.75)$ or moderate BCS $(>2.75)$ and also categorized into lower $(\leq 120)$ or higher DIM (>120 d after calving). Based on parity, milk yield was categorized (above or below the average production within a parity) for primiparous cows (lower, $\leq 33.0$ $\mathrm{kg} / \mathrm{d}$, and higher, $>33.0 \mathrm{~kg} / \mathrm{d}$ ) and multiparous cows (lower, $\leq 38.0 \mathrm{~kg} / \mathrm{d}$, and higher, $>38.0 \mathrm{~kg} / \mathrm{d}$ ) for further analyses.

From a subset of 418 cows, ovaries were evaluated using a transrectal ultrasound machine (Ibex Lite, E.I.

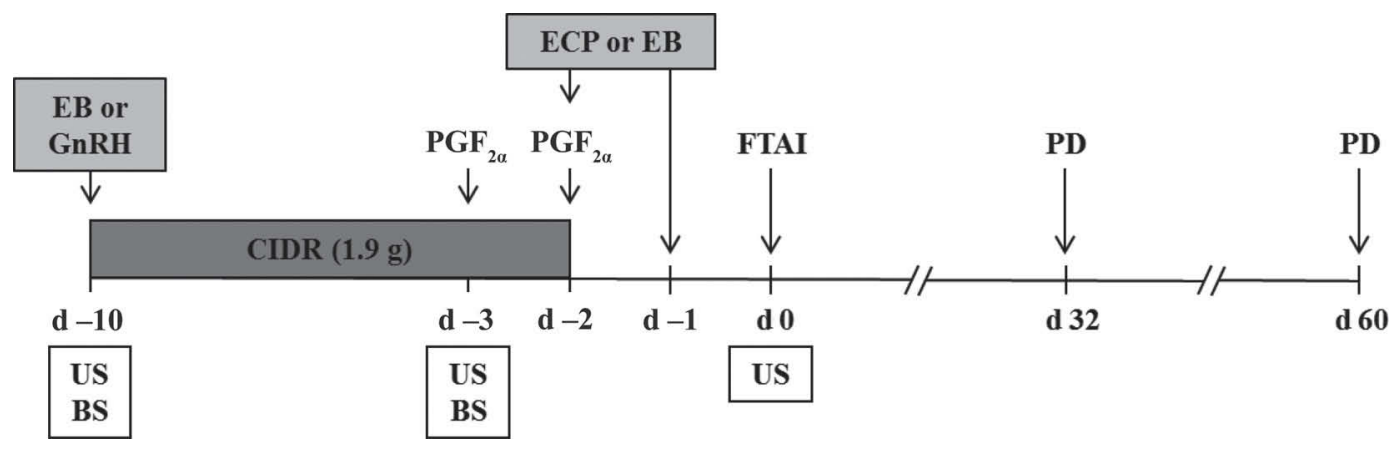

Figure 1. Diagram of activities for the study. Study d -10 is the day the fixed time artificial insemination (FTAI) protocol began with cows receiving an intravaginal progesterone $[\mathrm{P} 4$; controlled internal drug release $(\mathrm{CIDR})]$ implant and $2.0 \mathrm{mg}$ of estradiol benzoate $(\mathrm{EB})$ or $100 \mu \mathrm{g}$ of gonadorelin $(\mathrm{GnRH})$. On $\mathrm{d}-3$ and $-2,500 \mu \mathrm{g}$ of cloprostenol sodium $\left(\mathrm{PGF}_{2 \alpha}\right)$ was administered. On $\mathrm{d}-2$, the $\mathrm{P} 4$ implant was removed, and cows either received $1.0 \mathrm{mg}$ of estradiol cypionate (ECP) on the same day, or $1.0 \mathrm{mg} \mathrm{EB}$ on $\mathrm{d}-1$. All cows were inseminated on d 0 . All treatments were done near the same time of day in the morning. Pregnancy diagnosis (PD) was performed on d 32 and confirmed on d 60 . The study was performed using a completely randomized design with a $2 \times 2$ factorial arrangement of treatments. US $=$ ovary scanned by ultrasound; BS = blood sample for circulating P4 concentration. 
Medical Imaging, Loveland, CO) with an 8-5 MHz multifrequency linear-array transducer on $\mathrm{d}-10,-3$, and 0 of the protocols. On $\mathrm{d}-10$, ovaries were evaluated by ultrasound to confirm the presence or absence of a CL and to measure the diameter of the largest follicle. Ovaries were again evaluated by ultrasound on $\mathrm{d}-3$ to confirm the presence or absence of CL and to determine whether CL regression occurred between d -10 and -3 and whether ovulation occurred following the treatments on $d-10$. Ultrasound evaluation was also performed on d 0 to measure the diameter of the ovulatory follicle. All measurements were done as described by Sartori et al. (2004).

\section{Blood Collection and P4 Assay}

From a subset of 340 cows on d -10 and 376 on d -3 , blood samples were collected by puncture of the coccygeal vein or artery into $10-\mathrm{mL}$ evacuated tubes (Vacutainer; Becton Dickinson, Franklin Lakes, NJ) for P4 measurements, immediately before administration of treatments on $\mathrm{d}-10$ and on -3 . Immediately after collection, samples were placed in ice and transported to the laboratory within $5 \mathrm{~h}$ and kept refrigerated overnight. Blood tubes were centrifuged at $1,900 \times g$ for 15 min at $4^{\circ} \mathrm{C}$ and serum was frozen at $-20^{\circ} \mathrm{C}$ for further analyses of $\mathrm{P} 4$ by a solid-phase RIA using a commercial kit (Coat-A-Count; Siemens Healthcare Diagnostic, Los Angeles, CA). The assay sensitivity was $0.01 \mathrm{ng} / \mathrm{mL}$ and the intra- and interassay coefficients of variation were 4.27 and $9.11 \%$, respectively.

\section{Pregnancy Diagnosis and Reenrollment of Previously Synchronized Cows}

Pregnancy diagnosis was done at $32 \mathrm{~d}$ after AI by transrectal ultrasonography of the reproductive tract by confirming an embryo heartbeat. Pregnant cows were reconfirmed at $60 \mathrm{~d}$ after AI. Pregnancy per AI was calculated at d 32 and 60 as well as pregnancy loss between these 2 evaluations. At any time during the experiment, cows that were diagnosed not pregnant were reenrolled in the experiment for further resynchronization.

\section{Statistical Analysis}

To test the hypotheses for the main treatment effects at the beginning of the protocol, a 1-tailed test was used, based on our previous hypothesis that $\mathrm{GnRH}$ would be superior to EB at the beginning of a protocol. At the end of the protocol, we were not certain of which treatment would be better due to lack of previous results and, therefore, a 2-tailed test was used. To test for interactions between treatments, 2-tailed tests were used. The sample size was calculated using the Minitab statistical software (version 17.3.1; Minitab Inc., State College, PA) to detect statistical significance considering $\alpha=0.05$ and $\beta=0.20$. For binary data, 500 cows per treatment were deemed necessary to detect an increase of approximately 5 percentage units (e.g., 30.0 vs. $35.2 \%$ ), only taking into account the main effect of hormonal treatment. For serum P4 concentration, a standard deviation of $3.0 \mathrm{ng} / \mathrm{mL}$ was used to detect a difference of $0.7 \mathrm{ng} / \mathrm{mL}$. For this, the number of cows needed per treatment was approximately 145 .

Categorical data were analyzed by logistic regression using the GLIMMIX procedure of SAS version 9.3 (SAS/STAT, SAS Institute Inc., Cary, NC) fitting a binary distribution response. The models included the fixed effects of treatment on $\mathrm{d}-10$, treatment on $\mathrm{d}$ -2 (or $\mathrm{d}-1$ ), parity as primiparous and multiparous, categorized milk yield within parity as below or above the mean value, categorized DIM as below or above 120 DIM, categorized BCS as low or moderate, season (summer and fall as hot, winter and spring as cold), the interactions between treatments at the beginning and at the end of the protocol, treatments and parity, treatments and categorized milk yield, treatments and categorized DIM, treatments and categorized BCS, and treatments and season. The estimates were back-transformed using the ILINK function of SAS to generate the adjusted Tukey percentages, and the results are expressed as least square means \pm standard error of means. The Kenward-Roger method was used to calculate the denominator degrees of freedom to approximate the F-tests in the mixed models. Model fitting was evaluated using the fit statistics.

The LOGISTIC procedure of SAS was used for logistic regression to model the probability of ovulation after GnRH and EB treatments as a function of P4 concentration at the beginning of the protocol, and the probability of pregnancy on d 60 after AI as a function of $\mathrm{P} 4$ concentration on $\mathrm{d}-10$ and -3 .

The continuous data, such as size of the largest follicle on $\mathrm{d}-10$, size of the largest follicle on $\mathrm{d} 0$, and serum P4 concentrations on $\mathrm{d}-10$ and -3 , were analyzed using the MIXED procedure of SAS version 9.3. Data were tested for normality of residuals using the UNIVARIATE procedure of SAS. The P4 data were analyzed as nonparametric using the KruskalWallis test ordered by the RANK procedure of SAS. The models included the fixed effects of treatment on $\mathrm{d}-10$, treatment on $\mathrm{d}-2$ ( or $\mathrm{d}-1$ ), parity, categorized milk, categorized DIM, categorized BCS, season, the interactions between treatments at the beginning and at the end of the protocol, treatments and parity, treatments and categorized milk yield, treatments and 
Table 1. Results (LSM \pm SE) from cows that had the follicle wave synchronized on $\mathrm{d}-10$ of the fixed-time artificial insemination (FTAI) protocol with estradiol benzoate (EB) or with $\mathrm{GnRH}$

\begin{tabular}{|c|c|c|c|}
\hline Item & $\mathrm{EB}^{1}$ & $\mathrm{GnRH}^{1}$ & $P$-value \\
\hline Serum P4 concentration on $\mathrm{d}-10, \mathrm{ng} / \mathrm{mL}$ (no.) & $3.0 \pm 0.2(163)$ & $3.2 \pm 0.2(172)$ & 0.27 \\
\hline CL on $\mathrm{d}-3, \%$ (no./no.) & $58.3 \pm 3.6(113 / 197)$ & $77.3 \pm 2.9(168 / 220)$ & $<0.01$ \\
\hline CL regression between $\mathrm{d}-10$ and $-3,{ }^{2} \%$ (no./no.) & $43.8 \pm 4.2(60 / 137)$ & $24.7 \pm 3.4(39 / 158)$ & $<0.01$ \\
\hline Diameter of the largest follicle on $\mathrm{d}-10, \mathrm{~mm}$ (no.) & $12.8 \pm 0.3(197)$ & $12.9 \pm 0.4(221)$ & 0.39 \\
\hline Ovulation after $\mathrm{d}-10,{ }^{3} \%$ (no./no.) & $25.0 \pm 3.1(49 / 197)$ & $35.9 \pm 3.3(79 / 220)$ & 0.02 \\
\hline \multicolumn{4}{|l|}{ Pregnancy per AI (all cows) } \\
\hline $32 \mathrm{~d}, \%$ (no./no.) & $33.7 \pm 2.2(161 / 485)$ & $38.2 \pm 2.2(203 / 550)$ & 0.07 \\
\hline $60 \mathrm{~d}, \%$ (no. $/$ no. $)$ & $28.9 \pm 2.1(138 / 485)$ & $32.9 \pm 2.1(173 / 549)$ & 0.09 \\
\hline Pregnancy loss, ${ }^{5} \%$ (no./no.) & $13.7 \pm 2.7(23 / 161)$ & $12.5 \pm 2.4(29 / 202)$ & 0.38 \\
\hline
\end{tabular}

${ }^{1}$ Cows received on d -10 of FTAI protocol an intravaginal progesterone (P4) implant and either $2.0 \mathrm{mg}$ of EB or $100 \mu \mathrm{g}$ of gonadorelin (GnRH).

${ }^{2}$ Percentage of cows with CL on $\mathrm{d}-10$, but without CL on $\mathrm{d}-3$ of the FTAI protocol.

${ }^{3}$ Percentage of cows with a new CL on $\mathrm{d}-3$ of the FTAI protocol.

${ }^{4}$ Percentage of cows with a follicle diameter $\geq 10.0 \mathrm{~mm}$ on $\mathrm{d}-10$ and with a new CL on the same ovary on $\mathrm{d}-3$ of the FTAI protocol.

${ }^{5}$ Pregnancy loss between gestation d 32 and 60 .

categorized DIM, treatments and categorized BCS, and treatments and season. The Kenward-Roger method was used to calculate the denominator degrees of freedom to approximate the F-tests in the mixed models. The estimates were back-transformed using the PDIFF function of SAS to generate the adjusted Tukey comparisons of means.

The results are expressed as least squares means \pm standard error of means. For all analyses, only variables with $P<0.20$ were kept in the final model, unless the variable was essential, such as treatments and their interactions. Differences were considered significant when $P \leq 0.05$, whereas a tendency was defined as $0.10 \geq P$ $>0.05$.

\section{RESULTS AND DISCUSSION}

Our first hypothesis was that starting the FTAI protocol with $\mathrm{GnRH}$ compared with EB would increase fertility in lactating dairy cows, due to improved endocrine environment during ovulatory follicle growth, in spite of, potentially, reduced follicular wave synchronization. This idea was based on the findings of previous studies that 25 to $30 \%$ of cows did not properly synchronize follicular wave emergence when E2- and P4based programs were used (Monteiro et al., 2015) and also that EB can induce luteolysis (Araujo et al., 2009). This hypothesis was conditionally accepted based on the results that initiation of the protocol with $\mathrm{GnRH}$ rather than $\mathrm{EB}$ treatment tended to increase $\mathrm{P} / \mathrm{AI}$ on d $32(P=0.07)$ and $60(P=0.09)$ after AI (Table 1$)$. The absolute difference in $\mathrm{P} / \mathrm{AI}$ was $4.5 \%(38.2-33.7)$, which translates into $13.4 \%$ more pregnancies from the protocol (4.5/33.7) based on d 32 pregnancy diagnosis or $13.8 \%$ more pregnancies $(4 / 28.9)$ based on the $\mathrm{d} 60$ diagnosis. We found no difference $(P=0.38)$ in pregnancy loss between EB and GnRH treatment (13.7 vs. $12.5 \%)$.

As shown in Table 1, at the start of the protocol $(d-10)$ a total of $70.7 \%$ of cows had a CL, with no differences between treatment groups $(P=0.27)$. Although this is higher than might be expected for cows after a previous breeding, it is similar to the $73.9 \%$ that was previously reported at the time a Resynch procedure was initiated (Bilby et al., 2013). We also found no differences between groups at the initiation of the protocol in circulating $\mathrm{P} 4(P=0.27)$ or size of the largest follicle of $\mathrm{d}-10(P=0.39)$ indicating that, even though the study began at an unknown day of the estrous cycle, cows were well randomized within treatment groups. However, $7 \mathrm{~d}$ after initiation of the protocol $(\mathrm{d}-3)$, a greater $(P<0.01)$ percentage of cows that were treated with $\mathrm{GnRH}$ had CL (77.3\%) compared with cows treated with EB (58.3\%), which was related to 2 factors. First, a greater $(P<0.01)$ percentage of cows treated with EB had CL regression between d -10 and $-3(43.8 \%)$ compared with cows treated with GnRH $(24.7 \%)$. Second, a greater $(P<0.01)$ percentage of cows had ovulation (new CL detected on $\mathrm{d}-3$ ) if they were treated with GnRH than EB. Consistent with these findings, circulating $\mathrm{P} 4$ concentrations on $\mathrm{d}$ -3 were also greater $(P<0.01)$ in cows treated with GnRH $(3.4 \mathrm{ng} / \mathrm{mL})$ than EB $(2.0 \mathrm{ng} / \mathrm{mL})$. Thus, cows treated with GnRH were more likely to have a CL at the time of $\mathrm{PGF}_{2 \alpha}$ treatment $(\mathrm{d}-3)$ and had greater circulating $\mathrm{P} 4$ concentrations during preovulatory follicle development than cows treated with EB. Consistent with this result, a previous study (Vasconcelos et 
al., 2011) compared initiation of a protocol with $\mathrm{GnRH}$ compared with $\mathrm{EB}$ and reported greater $(P<0.01)$ serum $\mathrm{P} 4$ at $7 \mathrm{~d}$ after protocol initiation for $\mathrm{GnRH}$ than EB (2.89 vs. $2.29 \mathrm{ng} / \mathrm{mL})$. Similarly, a previous study (Pereira et al., 2013a) comparing an E2 and P4 protocol to a GnRH-based protocol (5-d Cosynch) also reported greater $(P<0.01)$ circulating $\mathrm{P} 4$ concentrations for GnRH than EB (2.66 vs. $1.66 \mathrm{ng} / \mathrm{mL}$ ).

The finding of increased CL regression in response to $\mathrm{EB}$ is consistent with a recent study that reported that $\sim 55 \%$ of cows treated with $\mathrm{EB}$ at the beginning of an E2 and P4 protocol had luteolysis during the first $7 \mathrm{~d}$ of the protocol (Monteiro et al., 2015). Older research also reported that treatment with E2-esters (such as E2-valerate) induced CL regression in cows that were treated at various stages of the estrous cycle, although these studies used higher doses of estradiolesters than we used in our study (Wiltbank et al., 1961; Rajamahendran and Walton, 1990; Pratt et al., 1991). Moreover, when heifers were challenged with $1.0 \mathrm{mg}$ of $\mathrm{EB}$ on d 13 after ovulation, luteolysis was induced in $100 \%$ of heifers (Araujo et al., 2009). Thus, induction of premature luteolysis in some cows treated with EB can explain some of the differences in circulating $\mathrm{P} 4$ on $\mathrm{d}-3$ of a protocol initiated with EB compared with GnRH.

The other factor that could increase circulating P4 during the protocol in GnRH-treated cows was that a greater percentage of cows ovulated in response to GnRH at the start of the protocol than following EB. The ovulation incidence (Table 1) could be expressed comparing all cows that were treated with GnRH versus EB (35.9 vs. $25.0 \% ; P=0.02$ ) or if only cows with a follicle $\geq 10 \mathrm{~mm}$ at the initiation of the protocol were considered (33.6 vs. $17.1 \% ; P<0.01$ ). Of particular interest, as serum $\mathrm{P} 4$ concentrations increased, the probability of ovulation decreased $(P<$ 0.01) for both EB and GnRH treatments (Figure 2). The decrease in ovulatory response as circulating P4 concentrations increased was expected and is likely due to the previously reported decrease in the magnitude of the GnRH-induced LH surge in response to increasing circulating P4 concentrations (Colazo et al., 2008; Dias et al., 2010; Giordano et al., 2012a). It is possible that greater ovulation incidence may have occurred with a different $\mathrm{GnRH}$ analog, such as lecirelin or buserelin (Picard-Hagen et al., 2015), or with a greater dose of gonadorelin (Giordano et al., 2012a). It was also interesting that $17 \%$ of cows that were treated with EB also ovulated after initiation of the protocol, as demonstrated by a new CL that was present $7 \mathrm{~d}$ later (d -3 of the protocol). Treatment with a P4 implant in conjunction with $\mathrm{EB}$ at the initiation of the protocol is expected to prevent an E2-induced GnRH or LH surge, preventing subsequent ovulation (Bó et al., 1993; Souza et al., 2009). It seems likely that some, but not all, cows were undergoing a natural ovulatory process due to the random day of the cycle at protocol initiation. Therefore, we speculated that, in spite of the presence of a P4 implant, some of the cows had a GnRH or LH surge induced by the EB treatment and, as expected, ovulation was much more likely to occur in the presence of low rather than high circulating $\mathrm{P} 4$ concentrations (Figure 2). This is consistent with another study that observed ovulation in response to E2 treatment, in cows in the late estrous cycle, even if the cows were treated simultaneously with P4 (Kastelic et al., 2004).

One other important difference between treatments at the beginning of the protocol was that cows that initiated the protocol with $\mathrm{GnRH}$ rather than EB ovulated a larger diameter follicle at the end of the protocol (15.5 vs. $14.7 \mathrm{~mm} ; P=0.02)$. It is well known that treatment with EB at the initiation of the protocol inhibits gonadotropin secretion and will initiate a new follicular wave 3 to 5 d later (Bó et al., 1993; Sartori et al., 2003; Souza et al., 2009; Monteiro et al., 2015). In a 10-d protocol, this would produce only 1 to $4 \mathrm{~d}$ of follicle dominance ( 3 to $5 \mathrm{~d}$ until wave emergence, 3 to $4 \mathrm{~d}$ from emergence to follicular deviation) at the time of AI. In contrast, cows in the GnRH group that ovulated to the $\mathrm{GnRH}$ would have a new follicular wave during the first 1 to $2 \mathrm{~d}$ after treatment and follicular dominance of 3 to $6 \mathrm{~d}$ at time of AI. Cows in the GnRH group that did not ovulate to the GnRH could have substantial variability in degree of follicular dominance based on timing of follicular wave emergence. The larger ovulatory follicle is consistent with the idea that cows that initiated the protocol with GnRH had older follicles with a longer period of follicular dominance compared with cows treated with EB. Some studies have indicated that a greater period of follicular dominance is detrimental to follicles, leading to an aged oocyte at ovulation (Cerri et al., 2009; Wiltbank et al., 2011). However, juxtaposed to these changes, ovulation of a larger follicle will produce a larger CL (Sartori et al., 2002) and greater circulating P4 after AI (Vasconcelos et al., 2001), potentially leading to improved embryo elongation and development (Carter et al., 2008; Clemente et al., 2009). Furthermore, increased circulating P4 during preovulatory follicle development, as seen in the current study in cows that received GnRH at the beginning of the protocol, has been associated with decreased LH pulse frequency, which could help avoid overstimulation of the preovulatory follicle and associated oocyte (Wiltbank et al., 2011). Thus, increased circulating P4 during preovulatory follicle development, in spite of ovulating a larger and probably older follicle, may help explain the better fertility in cows 
Table 2. Results (LSM $\pm \mathrm{SE}$ ) for main effect of hormonal treatment at the end of the protocol ${ }^{1}$

\begin{tabular}{|c|c|c|c|}
\hline Item & $\mathrm{ECP}$ & $\mathrm{EB}$ & $P$-value \\
\hline $32 \mathrm{~d}, \%$ (no./no.) & $37.0 \pm 2.2(186 / 516)$ & $34.8 \pm 2.2(178 / 519)$ & 0.48 \\
\hline Pregnancy loss, ${ }^{2} \%$ (no./no.) & $15.4 \pm 2.8(31 / 185)$ & $11.1 \pm 2.4(21 / 178)$ & 0.22 \\
\hline
\end{tabular}

${ }^{1}$ Cows had ovulation induced with estradiol cypionate (ECP), on $\mathrm{d}-2$ of the fixed-time artificial insemination (FTAI) protocol, or with estradiol benzoate $(\mathrm{EB})$, on $\mathrm{d}-1$ of the protocol.

${ }^{2}$ Pregnancy loss between gestation d 32 and 60 .

that received GnRH at the initiation of the protocol, compared with those that received EB.

The second hypothesis of our study was that induction of ovulation with EB rather than ECP would produce better fertility to the timed AI. This hypothesis was rejected based on the lack of difference between $\mathrm{EB}$ and ECP in $\mathrm{P} / \mathrm{AI}$ at $\mathrm{d} 32(P=0.48)$ and $60(P=0.94)$ or in pregnancy loss $(P=0.22$; Table 2$)$. In our study, the time of ovulation and the percentage of cows that ovulated after treatments was not evaluated. Distinct differences exist in the patterns of circulating E2 after treatment with EB compared with ECP (Souza et al., 2005). Treatment with $1.0 \mathrm{mg}$ of EB compared with 1.0 mg of ECP produced an earlier peak in circulating E2 (16.0 vs. $30.7 \mathrm{~h}$ after treatment) and a greater maximum E2 concentration (9.6 vs. $3.4 \mathrm{pg} / \mathrm{mL}$ ), although, ECP treatment produced a longer period with elevated E2 than EB (Souza et al., 2005). It was expected that EB treatment at the end of the protocol would produce greater synchrony in the time of ovulation, perhaps improving timing of ovulation and AI, but that ECP could provide a more optimal endocrine environment during proestrus due to a slower and less abrupt increase in circulating E2. Although EB and ECP are likely to have produced these differences in profiles of circulating E2, in the present study, we found no difference in size of the ovulatory follicle $(P=0.90$; Table 2$)$.

Finally, our third hypothesis, that there would be an interaction or additive effects of the 2 treatments at the beginning or end of the protocol, was also rejected because we found no additive effects of treatments on $\mathrm{P} / \mathrm{AI}$ at d 32 or 60 or on pregnancy loss (Table 3 ). In addition, no interaction $(P>0.10)$ occurred between treatments (EB-ECP, EB-EB, GnRH-ECP, and GnRH$\mathrm{EB})$ for $\mathrm{P} / \mathrm{AI}$ on $\mathrm{d} 32(P=0.83)$ or $60(P=0.52)$ or pregnancy loss $(P=0.38)$. We did note a consistent increase in $\mathrm{P} / \mathrm{AI}(\sim 4$ to $5 \%)$ for cows that initiated the protocol with $\mathrm{GnRH}$ rather than $\mathrm{EB}$, regardless

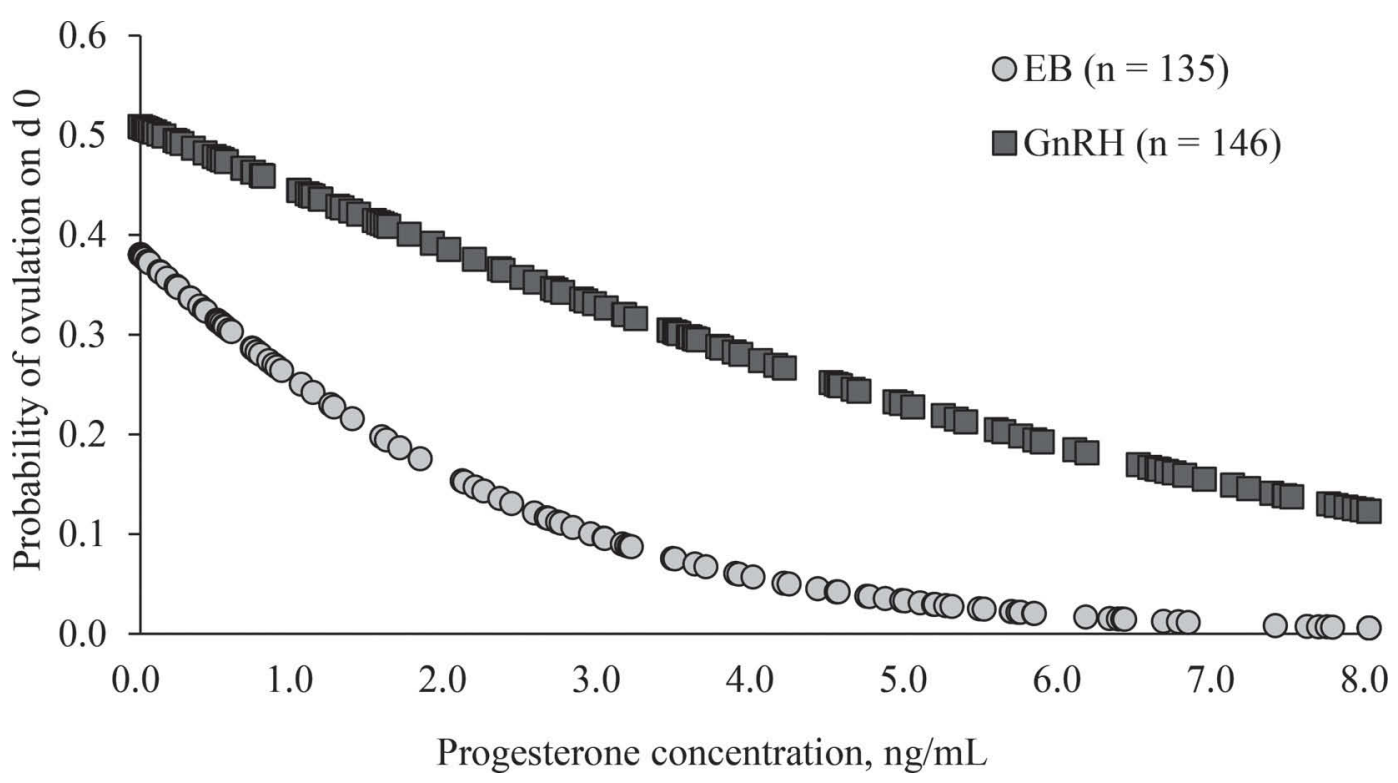

Figure 2. Probability of ovulation after estradiol benzoate (EB) or GnRH administration in relation to serum progesterone concentrations at the time of initiation of the protocol. Only cows with follicles greater than $10.0 \mathrm{~mm}$ on $\mathrm{d}-10$ were included in the analysis. We found a linear relationship for $\mathrm{EB}(P<0.01)$ as well as for GnRH $(P<0.01)$ treatments. 
Table 3. Fertility results (LSM $\pm \mathrm{SE}$ ) for all 4 treatment groups ${ }^{1}$

\begin{tabular}{|c|c|c|c|c|}
\hline Item & \multicolumn{2}{|c|}{$\mathrm{EB}$} & \multicolumn{2}{|c|}{$\mathrm{GnRH}$} \\
\hline \multicolumn{5}{|l|}{ Pregnancy per AI } \\
\hline 60 d, \% (no./no.) & $\begin{array}{r}29.9 \pm 3.0 \\
(68 / 233)\end{array}$ & $\begin{array}{r}27.9 \pm 2.9 \\
(70 / 252)\end{array}$ & $\begin{array}{r}32.1 \pm 2.9 \\
(86 / 282)\end{array}$ & $\begin{array}{r}33.8 \pm 3.0 \\
(87 / 267)\end{array}$ \\
\hline
\end{tabular}

${ }^{1}$ Cows received estradiol benzoate (EB) or GnRH at the beginning of the fixed-time artificial insemination (FTAI) protocol, for wave synchronization, and estradiol cypionate (ECP) or EB at the end of the protocol, for ovulation synchronization. Cows received on $\mathrm{d}-10$ of the FTAI protocol an intravaginal progesterone (P4) implant and either $2.0 \mathrm{mg}$ of EB or $100 \mu \mathrm{g}$ of gonadorelin (GnRH) to synchronize the follicle wave; $P$-value $>0.10$

${ }^{2}$ Cows received $1.0 \mathrm{mg}$ of ECP on $\mathrm{d}-2$, or $1.0 \mathrm{mg}$ of EB on $\mathrm{d}-1$ of the FTAI protocol.

${ }^{3}$ Pregnancy loss between gestation d 32 and 60 .

of whether ovulation was induced at the end of the protocol with EB or ECP.

Regardless of treatments, there was a quadratic effect of the circulating $\mathrm{P} 4$ concentrations either at $\mathrm{d}-10$ $(P=0.08)$ or $-3(P=0.05)$ on $\mathrm{P} / \mathrm{AI}$, based on the $\mathrm{d} 60$ pregnancy diagnosis (Figure $3 \mathrm{~A})$. In addition, analysis of the presence of a CL at $\mathrm{d}-10$ or -3 compared with $\mathrm{P} / \mathrm{AI}$ (Figure 3B) demonstrated a clear linear trend. Cows with no CL at the beginning and end of the protocol had the lowest P/AI $(11.6 \% ; 5 / 43)$, with cows with a CL present on only one of the days having intermediate values $(21.2 \% ; 36 / 170)$, and cows with CL at both $\mathrm{d}-10$ and -3 having the greatest P/AI (36.9\%; $75 / 203)$. As described above, high concentrations of P4 during ovulatory follicle growth is important for oocyte quality (Wiltbank et al., 2006, 2014), which is associ- ated with an increase in $\mathrm{P} / \mathrm{AI}$ in dairy cows (Bisinotto et al., 2013; Wiltbank and Pursley, 2014).

Finally, an analysis (Figure 4) was done of whether CL presence (yes) or absence (no) on $\mathrm{d}-10$ and -3 were related to treatments that were given at the initiation of the protocol (GnRH vs. EB). The EB group (d $-10)$ had greater $(P<0.01)$ proportion of cows with CL on $\mathrm{d}-10$ and without CL on $\mathrm{d}-3$ (yes-no). In contrast, GnRH group had greater $(P<0.01)$ proportion of cows with CL on $d-10$ and -3 (yes-yes) than EB group (Figure 4). The lack of difference between EBand GnRH-treated cows for the no-yes category may be explained by the low ovulatory response to GnRH and by the ovulatory response induced by EB (Figure 4). On the other hand, luteolysis induced by $2.0 \mathrm{mg}$ of EB on $\mathrm{d}-10$ may be responsible for more EB-treated cows
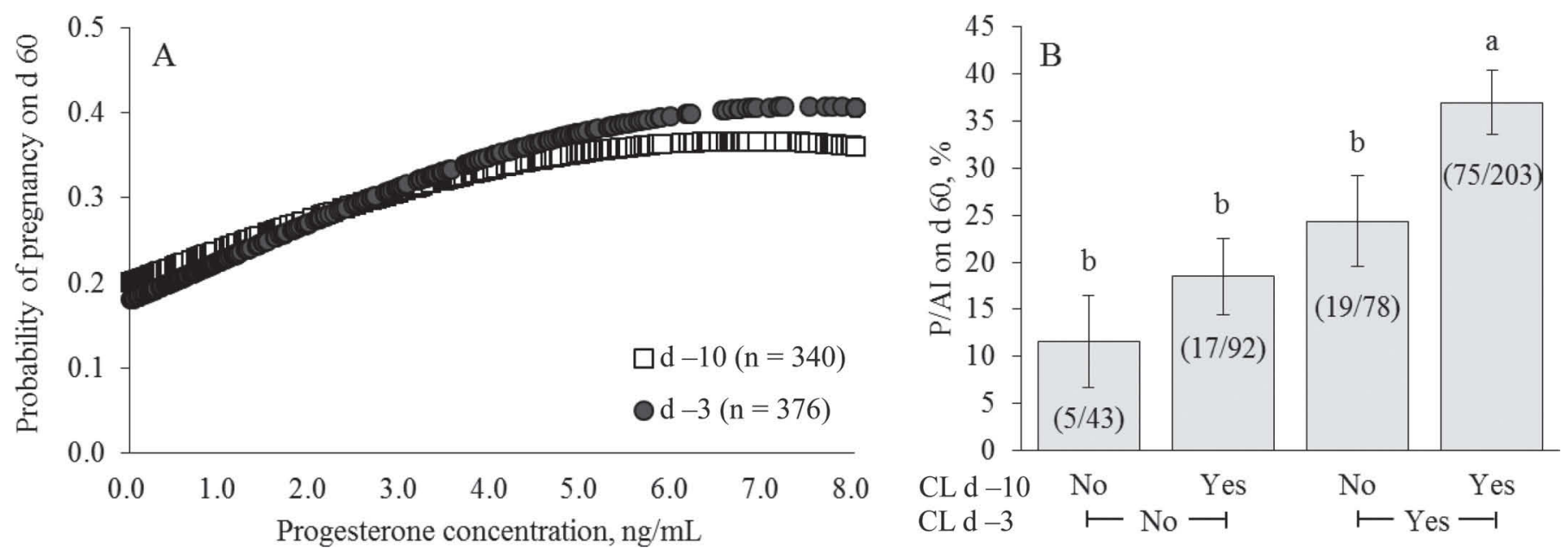

Figure 3. (A) Probability of pregnancy per AI (P/AI) compared with serum concentration of progesterone (P4), regardless of treatment, on $\mathrm{d}-10$ (quadratic effect; $P=0.08$ ) and $\mathrm{d}-3$ (quadratic effect; $P=0.05$ ) of a fixed-time artificial insemination (FTAI) protocol. (B) Pregnancy per AI, regardless of treatment, according to presence (yes) or absence (no) of corpus luteum (CL) on d -10 and -3 of the FTAI protocol. Different letters $(\mathrm{a}, \mathrm{b})$ mean statistical differences $(P \leq 0.05)$. 


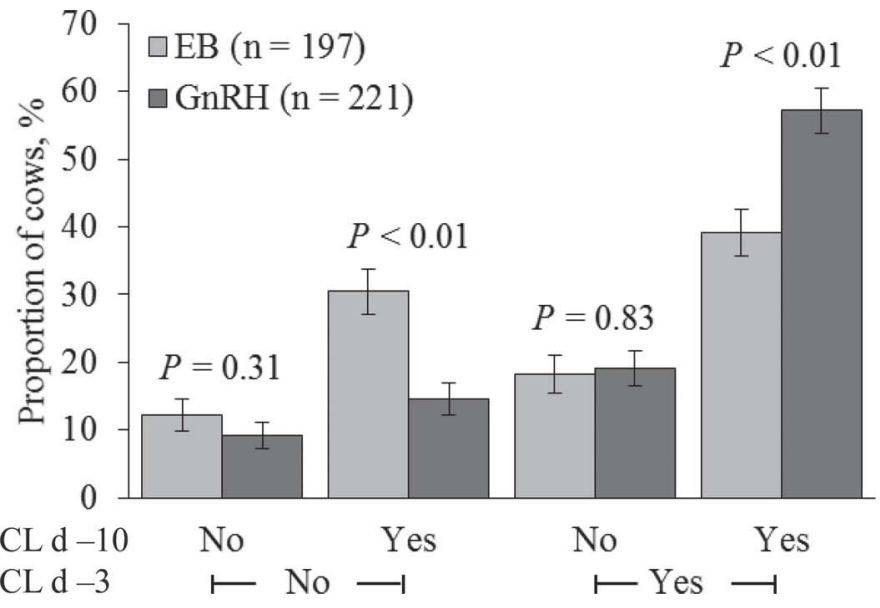

Figure 4. Proportion of cows with (yes) or without (no) corpus luteum (CL) on $\mathrm{d}-10$ and -3 of the fixed time artificial insemination (FTAI) protocol. $P$-value indicates differences between the hormonal treatment groups [estradiol (EB) vs. GnRH] within the specific CL category (no-no, no-yes, yes-no, yes-yes).

in the yes-no and fewer EB-treated cows in the no-yes categories compared with GnRH-treated cows. Thus, it seems likely a change in the endocrine environment occurred during preovulatory follicle development, likely to favor fertility in the GnRH treatment group, due to the increase in percentage of cows that have a CL at the time of $\mathrm{PGF}_{2 \alpha}$ treatment in the protocol.

Treatments at the beginning of the protocol affected $(P=0.02)$ ovulatory follicle diameter with cows treated with $\mathrm{GnRH}$ having larger ovulatory follicles than those treated with EB, as mentioned before (Table 1; Figure $5)$. However, treatments at the end of the protocol to synchronize ovulation (ECP vs. EB) did not affect $(P$ $=0.89$ ) the size of the ovulatory follicle (Table 2). Studies have shown a quadratic effect for the probability of pregnancy according to ovulatory follicle diameter (Sartori et al., 2006; Souza et al., 2007; Pereira et al., 2014). Another study described a linear effect between $\mathrm{P} / \mathrm{AI}$ and ovulatory follicle size with greater $\mathrm{P} / \mathrm{AI}$ with greater ovulatory follicle size in cows that had a CL present during the protocol (Pereira et al., 2015). In the present study, regardless of treatments, we observed that the P/AI on $\mathrm{d} 60$ after $\mathrm{AI}$ in cows with CL on $\mathrm{d}$ -10 and -3 was not affected by the ovulatory follicle size $(33.0 \pm 4.6$ vs. $34.9 \% \pm 7.3$ for follicle size $10-16$ $\mathrm{mm}$ vs. $>16 \mathrm{~mm}$, respectively; $P=0.83$ ). However, cows without $\mathrm{CL}$ on $\mathrm{d}-10$ or -3 that ovulated follicles $>16 \mathrm{~mm}$ had lower $(P=0.05) \mathrm{P} / \mathrm{AI}$ on $\mathrm{d} 60(16.7 \%$ $\pm 4.4)$. Interestingly, $88.9 \%(16 / 18)$ of the cows that ovulated larger follicles $(>18.0 \mathrm{~mm})$ and were treated with $\mathrm{EB}$ at the beginning of the protocol did not have CL on $\mathrm{d}-10$ or -3 , compared with $58.3 \%(21 / 36)$ of the GnRH-treated cows $(P<0.01)$. Although these

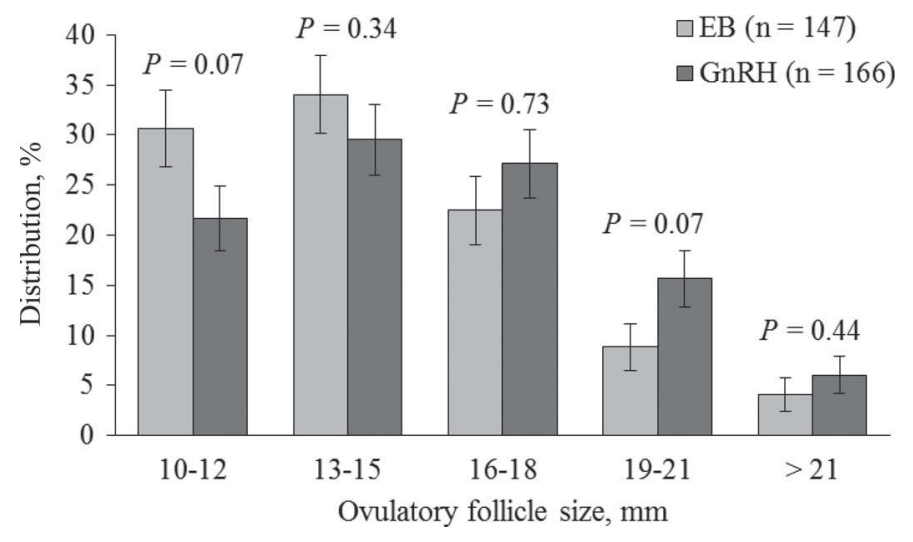

Figure 5. Distribution of ovulatory follicle diameter on d 0 of cows treated with estradiol benzoate (EB) or $\mathrm{GnRH}$ at the beginning of the protocol $(\mathrm{d}-10)$. An effect of treatment was observed $(P=0.02)$.

cows were treated with $\mathrm{E} 2$ and $\mathrm{P} 4$ on $\mathrm{d}-10$ to induce emergence of a new follicle wave (Bó et al., 1993), a previous study has demonstrated that atresia of the follicles did not happen in some of these cows and cows ovulated a persistent follicle (Monteiro et al., 2015). In this case, the circulating P4 induced by the CIDR implant was not enough to completely block the E2induced GnRH-LH release (Robinson et al., 2000) or EB and P4 did not efficiently block FSH release from the pituitary.

\section{CONCLUSIONS}

Cows that were treated with GnRH rather than EB at the initiation of a synchronization protocol tended to have better P/AI, probably due to increased circulating $\mathrm{P} 4$ concentrations during growth of the ovulatory follicle. The increased $\mathrm{P} 4$ was due to greater ovulation to the GnRH than the EB at the start of the protocol and reduced premature CL regression for $\mathrm{GnRH}$ compared with EB. However, treatments with either ECP or EB at the end of the protocol produced similar $\mathrm{P} / \mathrm{AI}$ in this study. Additionally, we found no additive effect or interactions on $\mathrm{P} / \mathrm{AI}$ between hormonal treatments at the beginning of the protocol ( $\mathrm{GnRH}$ or $\mathrm{EB}$ ) or hormonal treatments to synchronize ovulation at the end of the protocol (EB or ECP). Finally, independent of treatments, cows with CL at the initiation of the protocol as well as at the time of $\mathrm{PGF}_{2 \alpha}$ had greater fertility.

\section{ACKNOWLEDGMENTS}

The authors thank the owner and staff of São Jorge Farm (São Pedro, SP, Brazil) for the use of their cows and facilities. L F. Melo was supported by a scholarship from Coordination for the Improvement of Higher Edu- 
cation (CAPES, Brasilia, Brazil), P. L. J. Monteiro Jr. was supported by a scholarship grant \# 2011/113447, São Paulo Research Foundation (FAPESP, São Paulo, Brazil), and M. C. Wiltbank was supported by a scholarship grant \# 2011/08567-4 from FAPESP. This project was funded by a grant \#2011/11395-0 from FAPESP and by a grant \#460902/2014-8 from the Brazilian National Council for Scientific and Technological Development (CNPq, Brasilia, Brazil). Our appreciation is extended to Zoetis (São Paulo, Brazil) for providing the CIDR inserts, to MSD Animal Health (São Paulo, Brazil) for providing the Fertagyl, and to Vallée S.A. (São Paulo, Brazil) for providing Sincrosin.

\section{REFERENCES}

Araujo, R. R., O. J. Ginther, J. C. Ferreira, M. M. Palhao, M. A. Beg, and M. C. Wiltbank. 2009. Role of follicular estradiol-17beta in timing of luteolysis in heifers. Biol. Reprod. 81:426-437.

Bilby, T. R., R. G. S. Bruno, K. J. Lager, R. C. Chebel, J. G. N. Moraes, P. M. Fricke, G. Lopes Jr., J. O. Giordano, J. E. P. Santos, F. S. Lima, J. S. Stevenson, and S. L. Pulley. 2013. Supplemental progesterone and timing of resynchronization on pregnancy outcomes in lactating dairy cows. J. Dairy Sci. 96:7032-7042.

Binelli, M., R. Sartori, J. L. M. Vasconcelos, M. H. C. Pereira, P. L. J. Monteiro Jr., and R. S. Ramos. 2014. Evolution in fixed-time: From synchronization of ovulation to improved fertility. Pages 493-506 in Reproduction in Domestic Ruminants VIII. Vol. 1. 1st ed. J. L. Juengel, A. Miyamoto, C. Price, L. P. Reynolds, M. F. Smith, and R. Webb, ed. Context, Ashby de la Zouch, UK.

Bisinotto, R. S., E. S. Ribeiro, F. S. Lima, N. Martinez, L. F. Greco, L. Barbosa, P. P. Bueno, L. F. S. Scagion, W. W. Thatcher, and J. E. P. Santos. 2013. Targeted progesterone supplementation improves fertility in lactating dairy cows without a corpus luteum at the initiation of the timed artificial insemination protocol. J. Dairy Sci. 96:2214-2225

Bó, G. A., G. P. Adams, L. F. Nasser, R. A. Pierson, and R. J. Mapletoft. 1993. Effect of estradiol valerate on ovarian follicles, emergence of follicular waves and circulating gonadotropins in heifers. Theriogenology 40:225-239.

Bó, G. A., P. S. Baruselli, D. Moreno, L. Cutaia, M. Caccia, R. Tribulo, H. Tribulo, and R. J. Mapletoft. 2002. The control of follicular wave development for self-appointed embryo transfer programs in cattle. Theriogenology 57:53-72.

Burke, C. R., K. L. Macmillan, and M. P. Boland. 1996. Oestradiol potentiates a prolonged progesterone-induced suppression of $\mathrm{LH}$ release in ovariectomised cows. Anim. Reprod. Sci. 45:13-28.

Burke, C. R., M. L. Mussard, C. L. Gasser, D. E. Grum, and M. L. Day. 2003. Estradiol benzoate delays new follicular wave emergence in a dose-dependent manner after ablation of the dominant ovarian follicle in cattle. Theriogenology 60:647-658.

Carter, F., N. Forde, P. Duffy, M. Wade, T. Fair, M. A. Crowe, A. C. O. Evans, D. A. Kenny, J. F. Roche, and P. Lonergan. 2008. Effect of increasing progesterone concentration from Day 3 of pregnancy on subsequent embryo survival and development in beef heifers. Reprod. Fertil. Dev. 20:368-375.

Cavalieri, J., G. Hepworth, L. A. Fitzpatrick, R. W. Shephard, and K. L. Macmillan. 2006. Manipulation and control of the estrous cycle in pasture-based dairy cows. Theriogenology 65:45-64.

Cavalieri, J., G. Hepworth, K. I. Parker, P. J. Wright, and K. L. Macmillan. 2003. Effect of treatment with progesterone and oestradiol when starting treatment with an intravaginal progesterone releasing insert on ovarian follicular development and hormonal concentrations in Holstein cows. Anim. Reprod. Sci. 76:177-193.
Cerri, R. L. A., H. M. Rutigliano, R. C. Chebel, and J. E. P. Santos. 2009. Period of dominance of the ovulatory follicle influences embryo quality in lactating dairy cows. Reproduction 137:813-823.

Clemente, M., J. de la Fuente, T. Fair, A. Al Naib, A. Gutierrez-Adan, J. F. Roche, D. Rizos, and P. Lonergan. 2009. Progesterone and conceptus elongation in cattle: a direct effect on the embryo or an indirect effect via the endometrium? Reproduction 138:507-517.

Colazo, M. G., J. P. Kastelic, H. Davis, M. D. Rutledge, M. F. Martinez, J. A. Small, and R. J. Mapletoft. 2008. Effects of plasma progesterone concentrations on LH release and ovulation in beef cattle given GnRH. Domest. Anim. Endocrinol. 34:109-117.

Dias, F. C. F., M. G. Colazo, J. P. Kastelic, R. J. Mapletoft, G. P. Adams, and J. Singh. 2010. Progesterone concentration, estradiol pretreatment, and dose of gonadotropin-releasing hormone affect gonadotropin-releasing hormone-mediated luteinizing hormone release in beef heifers. Domest. Anim. Endocrinol. 39:155-162.

Ferguson, J. D., D. T. Galligan, and N. Thomsen. 1994. Principal descriptors of body condition score in Holstein cows. J. Dairy Sci. 77:2695-2703.

Giordano, J. O., P. M. Fricke, J. N. Guenther, G. Lopes, M. M. Herlihy, A. B. Nascimento, and M. C. Wiltbank. 2012a. Effect of progesterone on magnitude of the luteinizing hormone surge induced by two different doses of gonadotropin-releasing hormone in lactating dairy cows. J. Dairy Sci. 95:3781-3793.

Giordano, J. O., M. C. Wiltbank, J. N. Guenther, R. Pawlisch, S. Bas, A. P. Cunha, and P. M. Fricke. 2012b. Increased fertility in lactating dairy cows resynchronized with Double-Ovsynch compared with Ovsynch initiated $32 \mathrm{~d}$ after timed artificial insemination. J. Dairy Sci. 95:639-653.

Kastelic, J. P., M. G. Colazo, J. A. Small, D. R. Ward, and R. J. Mapletoft. 2004. Ovarian follicular dynamics in cows treated with a CIDR, estradiol and progesterone late in the estrous cycle. Reprod. Fertil. Dev. 16:129-130. (Abstract).

Lopes, G., J. O. Giordano, A. Valenza, M. M. Herlihy, J. N. Guenther, M. C. Wiltbank, and P. M. Fricke. 2013. Effect of timing of initiation of resynchronization and presynchronization with gonadotropin-releasing hormone on fertility of resynchronized inseminations in lactating dairy cows. J. Dairy Sci. 96:3788-3798.

Lopez, H., L. D. Satter, and M. C. Wiltbank. 2004. Relationship between level of milk production and estrous behavior of lactating dairy cows. Anim. Reprod. Sci. 81:209-223.

Monteiro, P. L. J., Jr., M. Borsato, F. L. M. Silva, A. B. Prata, M. C. Wiltbank, and R. Sartori. 2015. Increasing estradiol benzoate, pretreatment with gonadotropin-releasing hormone, and impediments for successful estradiol-based fixed-time artificial insemination protocols in dairy cattle. J. Dairy Sci. 98:3826-3839.

Norman, H. D., J. R. Wright, S. M. Hubbard, R. H. Miller, and J. L. Hutchison. 2009. Reproductive status of Holstein and Jersey cows in the United States. J. Dairy Sci. 92:3517-3528.

NRC. 2001. Nutrient Requirements of Dairy Cattle. 7th rev. ed. Natl. Acad. Sci., Washington, DC.

Pereira, M. H. C., A. D. P. Rodrigues, R. J. De Carvalho, M. C. Wiltbank, and J. L. M. Vasconcelos. 2014. Increasing length of an estradiol and progesterone timed artificial insemination protoco decreases pregnancy losses in lactating dairy cows. J. Dairy Sci. 97:1454-1464

Pereira, M. H. C., A. D. P. Rodrigues, T. Martins, W. V. C. Oliveira, P. S. A. Silveira, M. C. Wiltbank, and J. L. M. Vasconcelos. 2013a. Timed artificial insemination programs during the summer in lactating dairy cows: Comparison of the 5-d Cosynch protocol with an estrogen/progesterone-based protocol. J. Dairy Sci. 96:6904-6914.

Pereira, M. H. C., C. P. Sanches, T. G. Guida, A. D. R. Rodrigues, F. L. Aragon, M. B. Veras, P. T. Borges, M. C. Wiltbank, and J. L. M. Vasconcelos. 2013b. Timing of prostaglandin F-2 alpha treatment in an estrogen-based protocol for timed artificial insemination or timed embryo transfer in lactating dairy cows. J. Dairy Sci. 96:2837-2846.

Pereira, M. H. C., M. C. Wiltbank, L. F. S. P. Barbosa, W. M. Costa Jr., M. A. P. Carvalho, and J. L. M. Vasconcelos. 2015. Effect of adding a gonadotropin-releasing-hormone treatment at the begin- 
ning and a second prostaglandin F-2 alpha treatment at the end of an estradiol-based protocol for timed artificial insemination in lactating dairy cows during cool or hot seasons of the year. J. Dairy Sci. 98:947-959.

Picard-Hagen, N., G. Lhermie, S. Florentin, D. Merle, P. Frein, and V. Gayrard. 2015. Effect of gonadorelin, lecirelin, and buserelin on LH surge, ovulation, and progesterone in cattle. Theriogenology $84: 177-183$.

Pratt, S. L., J. C. Spitzer, G. L. Burns, and B. B. Plyler. 1991. Luteal function, estrous response, and pregnancy rate after treatment with norgestomet and various dosages of estradiol valerate in suckled cows. J. Anim. Sci. 69:2721-2726.

Pursley, J. R., M. O. Mee, and M. C. Wiltbank. 1995. Synchronization of ovulation in dairy-cows using PGF(2-alpha), and GnRH. Theriogenology 44:915-923.

Rajamahendran, R., and J. S. Walton. 1990. Effect of treatment with estradiol valerate on endocrine changes and ovarianfollicle populations in dairy-cows. Theriogenology 33:441-452.

Robinson, J. E., A. E. Healey, T. G. Harris, E. A. Messent, D. C. Skinner, J. A. Taylor, and N. P. Evans. 2000. The negative feedback action of progesterone on luteinizing hormone release is not associated with changes in $\mathrm{GnRH}$ mRNA expression in the ewe. J. Neuroendocrinol. 12:121-129.

Rutigliano, H. M., F. S. Lima, R. L. A. Cerri, L. F. Greco, J. M. Vilela, V. Magalhaes, F. T. Silvestre, W. W. Thatcher, and J. E. P. Santos. 2008. Effects of method of presynchronization and source of selenium on uterine health and reproduction in dairy cows. J. Dairy Sci. 91:3323-3336.

Sartori, R., A. Gumen, J. N. Guenther, A. H. Souza, D. Z. Caraviello, and M. C. Wiltbank. 2006. Comparison of artificial insemination versus embryo transfer in lactating dairy cows. Theriogenology 65:1311-1321.

Sartori, R., J. M. Haughian, R. D. Shaver, G. J. M. Rosa, and M. C. Wiltbank. 2004. Comparison of ovarian function and circulating steroids in estrous cycles of Holstein heifers and lactating cows. J. Dairy Sci. 87:905-920.

Sartori, R., G. J. M. Rosa, and M. C. Wiltbank. 2002. Ovarian structures and circulating steroids in heifers and lactating cows in summer and lactating and dry cows in winter. J. Dairy Sci. 85:28132822 .

Sartori, R., C. A. Suarez-Fernandez, R. L. Monson, J. N. Guenther, G. J. M. Rosa, and M. C. Wiltbank. 2003. Improvement in recovery of embryos/ova using a shallow uterine horn flushing technique in superovulated Holstein heifers. Theriogenology 60:1319-1330.

Souza, A. H., H. Ayres, R. M. Ferreira, and M. C. Wiltbank. 2008. A new presynchronization system (Double-Ovsynch) increases fertility at first postpartum timed AI in lactating dairy cows. Theriogenology 70:208-215.

Souza, A. H., A. P. Cunha, D. Z. Caraviello, and M. C. Wiltbank. 2005. Profiles of circulating estradiol-17 beta after different estrogen treatments in lactating dairy cows. Anim. Reprod. 2:224-232.

Souza, A. H., A. Gumen, E. P. B. Silva, A. P. Cunha, J. N. Guenther, C. M. Peto, D. Z. Caraviello, and M. C. Wiltbank. 2007. Supple- mentation with estradiol-17 beta before the last gonadotropinreleasing hormone injection of the ovsynch protocol in lactating dairy cows. J. Dairy Sci. 90:4623-4634.

Souza, A. H., S. Viechnieski, F. A. Lima, F. F. Silva, R. Araujo, G. A. Bo, M. C. Wiltbank, and P. S. Baruselli. 2009. Effects of equine chorionic gonadotropin and type of ovulatory stimulus in a timedAI protocol on reproductive responses in dairy cows. Theriogenology $72: 10-21$.

Stevenson, J. S., J. R. Pursley, H. A. Garverick, P. M. Fricke, D. J Kesler, J. S. Ottobre, and M. C. Wiltbank. 2006. Treatment of cycling and noncycling lactating dairy cows with progesterone during Ovsynch. J. Dairy Sci. 89:2567-2578.

Vasconcelos, J. L. M., D. T. G. Jardina, O. G. Sa, F. L. Aragon, and M. B. Veras. 2011. Comparison of progesterone-based protocols with gonadotropin-releasing hormone or estradiol benzoate for timed artificial insemination or embryo transfer in lactating dairy cows. Theriogenology 75:1153-1160.

Vasconcelos, J. L. M., R. Sartori, H. N. Oliveira, J. G. Guenther, and M. C. Wiltbank. 2001. Reduction in size of the ovulatory follicle reduces subsequent luteal size and pregnancy rate. Theriogenology 56:307-314.

Vasconcelos, J. L. M., R. W. Silcox, G. J. M. Rosa, J. R. Pursley, and M. C. Wiltbank. 1999. Synchronization rate, size of the ovulatory follicle, and pregnancy rate after synchronization of ovulation beginning on different days of the estrous cycle in lactating dairy cows. Theriogenology 52:1067-1078.

Washburn, S. P., W. J. Silvia, C. H. Brown, B. T. McDaniel, and A. J. McAllister. 2002. Trends in reproductive performance in southeastern Holstein and Jersey DHI herds. J. Dairy Sci. 85:244-251.

Wiltbank, J. N., J. E. Ingalls, and W. W. Rowden. 1961. Effects of various forms and levels of estrogens alone or in combinations with gonadotrophins on the estrous cycle of beef heifers. J. Anim. Sci. 20:341-346.

Wiltbank, M., H. Lopez, R. Sartori, S. Sangsritavong, and A. Gumen. 2006. Changes in reproductive physiology of lactating dairy cows due to elevated steroid metabolism. Theriogenology 65:17-29.

Wiltbank, M. C., G. M. Baez, F. Cochrane, R. V. Barletta, C. R. Trayford, and R. T. Joseph. 2015. Effect of a second treatment with prostaglandin F-2 alpha during the Ovsynch protocol on luteolysis and pregnancy in dairy cows. J. Dairy Sci. 98:8644-8654.

Wiltbank, M. C., and J. R. Pursley. 2014. The cow as an induced ovulator: Timed AI after synchronization of ovulation. Theriogenology $81: 170-185$.

Wiltbank, M. C., R. Sartori, M. M. Herlihy, J. L. M. Vasconcelos, A. B. Nascimento, A. H. Souza, H. Ayres, A. P. Cunha, A. Keskin, J. N. Guenther, and A. Gumen. 2011. Managing the dominant follicle in lactating dairy cows. Theriogenology 76:1568-1582.

Wiltbank, M. C., A. H. Souza, P. D. Carvalho, A. P. Cunha, J. O. Giordano, P. M. Fricke, G. M. Baez, and M. G. Diskin. 2014. Physiological and practical effects of progesterone on reproduction in dairy cattle. Animal 8:70-81. 